\title{
TIẾP CẬN HƯớNG DỐI TƯợNG CHO HỆ THỐNG THÔNG TIN KHO BAC NHÀ NƯỚC
}

\author{
PHAN ĐINH LỢI ${ }^{(1)}$, NGUYỄN THÚC HẢI ${ }^{(2)}$
}

\begin{abstract}
The State Treasury of Vietnam (VNST) has been facing computerization need to carry out its heavy duty. In order to set up the information system for VNST, one approach of system analysis and design must be chosen. With its advantage features, Object-Oriented Approach is popularly used in the current information system community. The Object-Oriented Approach for the information system of VNST is introduced. For the whole system, this approach can reduce significantly the development cost and time, meanwhile keeping the reliant of the life-cycle. The object-Oriented system analysis and design for the personnel subsystem has been described as an illustration of the technique in details.
\end{abstract}

\section{DẶT VẤN D产}

Kho bạc Nhà nước (KBNN) có các chức năng và nhiệm vụ sau đây [3]:

- Chứa năng quán lý nhà nước về quỹ Ngân sách Nhà nước (NSNN) bao gồm cả quỹ ngoại tệ tập trung, quỹ dự trữ tài chính Nhà nước, tî̀n, tài sản tạm thu, tạm giữ.

- Huy động vốn cho NSNN và cho đầu tư phát triển.

- Tập trung và phán ánh các khoán thu NSNN, bao gồm cá thu viện trợ vay nợ trong và ngoài nước và điều tiết thu cho các cấp ngân sách. Tổ chức chi và kiểm soát chi NSNN cho tù̀ng đối tượng theo dự toán NSNN được duyệt.

- Kiểm soát và thực hiện xuất nhập các quỹ dự trũ̃, tài sản tạm thu tạm giữ.

- Tỗ chức huy động vốn cho NSNN và cho đầu tư phát triển. Thực hiện nhiệm vụ phát hành trái phiếu trong và ngoài nước theo quy định của Chính phủ.

- Tỗ chức kế toán, thống kê và báo cáo quyết toán quỹ NSNN và các quỹ tài chính khác do Kho bạc quán lý. Tổ chức thanh toán, điều hòa vốn và tiền mặt trong toàn hệ thống KBNN.

- Tổ chức việc cấp phát và cho vay theo các chương trình mục tiêu của Chính phủ.

Để thực hiện tốt các nhiệm vụ trên, việc xây dựng hệ thống thông tin KBNN là vô cùng cần thiết. Theo nghiên cứu tiền khả thi [3], hệ thống thổng tin KBNN bao gồm các phân hệ sau:

- Quán lý thu/chi NSNN: nhằm trợ giúp KBNN thực hiện chức năng quản lý thu/chi NSNN.

- Quán lý Tín dụng - Cấp phát - Kho quỹ: nhằm trợ giúp KBNN thực hiện chức năng quán lý quỹ NSNN, huy động vốn cho NSNN và cho đầu tư phát triển.

- Kế toán - thanh toán: thực hiện nghiệp vụ kế toán Kho bạc và thanh toán.

- Kế hoạch - thống kê và thông tin phục vụ lãnh đạo: thực hiện nghiệp vụ lên kế hoạch, thống kê và qua đó cấp phát thông tin cho hệ thông tin phục vụ lãnh đạo.

- Quán trị điều hành nội bộ: thực hiện công tác quán lý nội bộ và tự động hóa trong công tác văn phòng toàn bộ hệ thống KBNN.

Có hai cách tiếp cận để xây dựng hệ thống thông tin KBNN, cách thứ nhất là tiếp cận theo hrớng thư tục, cách thứ hai là tiếp cận huớng đối tuợng.

Quá trình phát triển phần mềm theo hướng thủ tục (procedure-oriented) hay còn gọi là hướng chức năng được thể hiện trong các mô hình "thác nước" ("waterfall"), mô hình phát triển phần mềm hình mấu (prototype). Các mô hình thiết lập phần mềm hướng thủ tục như trên sứ dụng kỹ thuật phân rã chức năng theo cách tiểp cận top-down thành các đơn thể (module). Kỹ thuật 
này thông dịch không gian bài toán sang không gian lời giải. Cách tiếp cận này có các nhược điểm chính là: Thứ nhất, không cho phép thực hiện được những thay đổi theo kịp tiển bộ công nghệ phần mềm. Thứ hai, bước chuyển từ phân tích sang thiết kể là không dêx dàng và thiếu chặt chẽ , hầu như chỉ dựa vào kinh nghiệm riêng của mỗi nhà thiết kế. Thứ ba, dữ liệu không được chú ý, chỉ đóng vai trò thứ yếu, điều này gây cản trở rất lón cho việc mô tả các thực thể trong thế giới thực. Thứ tư, mối liên quan giữa dữ liệu và xư lý là mờ nhạt, chỉ thể hiện hình thức luồng dữ liệu găn với xử lý. Thứ năm, không thuận lợi cho việc sử dụng lại và kế thừa vì chúng găn chặt với môi trường dữ liệu và kiến trúc xử lý. Thứ sáu, việc chỉnh sửa và cập nhật cũng như việc bảo trì là khó khăn (xem [2]).

Cách tiếp cận hướng đối tượng với nhũng ưu điểm của nó sẽ khăc phục được những nhược điểm của các hướng tiếp cận khác, vì thể đã được ứng dụng trong việc xầy dựng các thông tin KBNN. Trong phần tiếp theo những thảo luận về những đặc trưng cơ bản và những tính ưu việt của phân tích, thiết kế hướng đối tượng sẽ được trình bày kỹ.

\section{PHÂN TÍCH VÀ THIÊT KỂ HƯƠNG ĐỐI TƯợNG}

\section{Phân tích hướng đổi tượng}

Đối tượng là gì?

Là một phần tử trừu tượng hóa của hệ thống bao gồm 3 mặt: i) các thông tin được "cất giữ"; ii) các xự lý cho phép tác động lên các dữ liệu đó; iii) một cách ứng xử, mô tá nhờ các trạng thái ổn định và cho phép xác định khi nào và các điều kiện nào thì các xử lý có thể được áp dụng lên các dữ liệu.

\section{Sự phân cấp các đổi tượng}

Có 4 sự phân cấp mà các phương pháp hướng dữ liệu nói chung và hướng đối tượng nói riêng đã đề cập đến: i) tổng hòa/đặc thù; ii) lóp/cá thể; iii) chung/riêng; iv) sự phân cấp "là một" được thể hiện bởi khái niệm kế thừa: lớp dưới kế thừa các tính chất và các xừ lý của một lớp trên.

Giao lưu giữa các đổi tượng

Hình thức giao lưu phổ biến là các ủy thác. Hình thức giao lưu khác - yếu hơn - là các biến cố. Còn một hình thức giao lưu khác cũng hay dùng, đó là giao lưu cơ chể dịch vụ, một hàng đợi hay một "bảng đen", còn đối tượng có liên quan tới thông tin đó, theo dõi trền hàng đợi, tiếp nhận thông tin và xừ lý nó khi trạng thái nội tại cưa chúng cho phép. Cách giao lưu này đặc biệt thích hợp với kiến trúc khách-chủ hay phân tán.

Các bước tiến hành trong phân tích hương đổi tượng

Để phân tích hướng đối tượng một hệ thống phức tạp, cần thực hiện 10 quy tắc sau [1]:

1) Định nghĩa khung cảnh của hệ thống.

2) Tăng cường khung cảnh với các lĩnh vực giao diện.

3) Bỗ sung các lĩnh vực khác.

4) Thành lập bản đồ các lĩnh vực của hệ thống.

5) Chia cắt mỗi lĩnh vực thành các hệ thớng con.

6) Xác định các đối tượng phân tích trong mỗi hệ thống con.

7) Mô tả động thái của các của các đối tượng.

8) Thành lập các mô hình tổng hợp.

9) Hoàn thiện, lặp đi lại lại và tinh chế.

10) Thành lập sự tham chiếu chức năng.

\section{Thiết kể hướng đối tượng}

Thiết kế hướng đối tượng là phương pháp thiết kế được kết hợp bởi ba phạm trù thiết kế: thiết kế dữ liệu, thiết kế kiến trúc và thiết kế thủ tục. Bằng việc xác định các đối tượng, các trừu tượng hóa (abstractions) dữ liệu được xây dựng. Bằng định ṇghĩa các phép toán, các đơn thể 
(modules) được cụ thể hóa và các cấu trúc phần mềm được thiết lập. Bằng việc xác định một cơ chể cho việc sứ dụng các đối tượng, các giao diện được mô tả (xem [4]).

Phương pháp thiết kế này thực hiện theo nguyên lý che giấu thông tin. Khác với các tiếp cận hướng chức năng là nó xem hệ thống phần mềm là tập các đối tượng tương tác với nhau. Thiết kể hướng đối tượng có những ưu điểm chính như sau: Thứ nhất, loại bỏ được những mî̀n dũ̃ liệu dùng chung thông qua cơ chể trao đổi thông tin giữa các đối tượng băng các thông báo. Thứ hai, các đối tượng được thiết kế là các thực thể độc lập; điều này đảm bảo hệ thống có tính dễ mớ rộng và dễ thích nghi, đáp ứng được nhiều tính chất quan trọng của sản phẩm phần mềm. Thứ ba, các đối tượng có thể được tổ chức phân tán hoặc song song hay tuần tự tùy theo yêu cầu của bài toán ứng dụng khả năng kỹ thuật thực tế cưa dự án phát triển tin học ứng dụng. Nhiệm vụ của thiết kế hướng đối tượng là xác định các đối tượng trong bài toán, chuyển chúng sang không gian lời giải, xây dựng mô hình kiến trúc và mô hình tính toán cho hệ thống phần mềm (xem [2]).

Cách tiếp cận thiết kế hướng đối tượng gồm các bước [2]:

1) Xác định các lời giải và các đối tượng, các thành phần cơ bản cưa lời giải.

2) Xây dựng các đặc tả cho các đối tượng, các lớp và mối quan hệ giữa chúng.

3) Xây dựng cấu trúc phân cấp cho các lớp.

4) Thiết kể các lớp.

5) Thiết kế các hàm thành phần của các lớp.

6) Thiết kế chương trình chính.

\section{TIẾP CẬN HƯớNG ĐỐI TƯợG CHO Hệ THÔNG TIN KBNN}

\section{Chiển lược chung đề tiểp cận cho toàn hệ thống thông tin KBNN}

Như đã trình bày ở trên, hệ thống thông tin KBNN rất lớn, công việc phân tích và thiết kế cũng như là việc cài đặt cho toàn hệ thống này là một công việc khổng lồ. Để có thể quản lý được tất cả khối lượng công việc ấy đồng thời phải quán triệt tính thống nhất về cơ sở dữ liệu cho toàn hệ thống nhằm tránh sự dư thừa thông tin và giữ được tính nhất quán thông tin, theo chúng tôi cần phải xác định được chiến lược chung tiếp cận hệ thống như sau:

a) Mô đun hóa hệ thống. Theo chức năng của các ứng dụng, xây dựng các phầm mềm ứng dụng độc lập với nhau về mặt chương trình nhưng lại quan hệ chặt chẽ với nhau về mặt dữ liệu; chúng được ứng dụng trên một nền CSDL thống nhất.

b) Xây dựng mô hình CSDL chung cho toàn hệ thống. Mặc dù công việc phân tích và thiết kế hệ thống là hướng đối tượng, nhưng nền lại là CSDL quan hệ. Vì thể việc xây dựng các phần CSDL cho từng ứng dụng sẽ có được các mô hình thực thể liên kết tương ứng. Trên cơ sớ làm phép "hội" các mô hình thực thể này, CSDL chung cho toàn ngành KBNN được thiết lập, tránh được sự dư thừa thông tin.

c) Cơ sơ dữ liệu cho KBNN là phân tán. Với việc đưa vào các mã địa phương thống nhất trong ngành nên việc lưu trữ và tìm kiếm thông tin theo các thông tin chi tiết có thể cho phép diễn ra trên pham vi toàn quốc của ngành $K B N N$. Việc "định vị" thông tin như vậy nhờ vào thư viện mã địa phương và địa chỉ IP tương ứng trên mạng WAN của ngành cũng như phăi viện đến các thiết bị viến thông như ROUTER, MODEM.

d) Dùng công nghệ WEB. Mặc dù việc truy nhập cơ sở dữ liệu từ xa theo mô hình Client/Server được đưa ra, có nghĩa là một người có trách nhiệm trong hệ thống KBNN có thể truy nhập tới bất kỳ CSDL của một cơ quan KBNN cấp nào để tra cứu thông tin cần thiết. Nhưng việc lên các trang báo cáo tự động trong dạng siêu văn bản (HTML) tại mọi cơ quan KBNN sẽ tiết kiệm thời gian cho lãnh đạo xem xét các thông tin quan trọng của ngành. Việc làm mói trang báo cáo là hàng ngày, thậm chí ngay tức thì, do đó thông tin quán lý của KBNN là rất mới và khách quan (do việc lền trang báo cáo là một chương trình tự động chiết xuất thông tin từ cơ sở dữ liệu của cơ quan KBNN đó). 
e) Áp dụng tiếp cận hướng đởi tượng cho từng ứng dụng. V1 việc xây dựng các phần mềm ứng dụng độc lập với nhau về chương trình, nên việc áp dụng tiếp cận đó cho từng úng dụng là hoàn toàn thích hợp.

f) Phân loại và đánh số các đổi tượng. Việc phân loại các đối tượng và việc đánh số các đối tượng là công việc nhất thiết phải làm để bảo đảm tính thống nhất của các đối tượng trong toàn hệ thống. Tính thống nhất này đảm bảo tính kế thừa trong thiết kế và xây dựng chương trình, mặt khác nó giúp cho chúng ta tránh được những khó khăn trong việc cài đặt hệ thông tin và bảo trì chúng. Tài liệu thiết kể kỹ thuật chi tiết của các hệ thông tin nhất thiết phải có báng chỉ số đối tượng.

\section{Phân tích và thiết kể hướng đối tượng hệ thông tin quán lý nhân sự KBNN}

Trong phần này chúng tôi đưa ra một ví dụ minh họa cho việc áp dụng lý thuyết phân tích và thiết kế hướng đối tượng trong xây dựng hệ thống thông tin KBNN.

\section{a) Hệ thông tin nhân sự cưa KBNN}

Hệ thông tin quán lý nhân sự là phầm mềm quán lý các thông tin về cán bộ làm việc trong các cơ quan của KBNN. Các thông tin quản lý bao gồm các nhóm như sau: Các thông tin sơ lược; Quá trình đào tạo; Quá trình công tác; Diễn biển lương; Diển biến chức vụ; Diễn biển danh hiệu; Khen thường / Kỷ luật; Thông tin về ngoại ngữ; Thông tin về các công trình; Quá trình được bồi dưỡng về chính trị; Thông tin về quân đội; Quá trình được bầu cứ; Diễn biến lịch sữ bán thân; Thông tin và thân nhân. Chương trình phải được xây dựng trên chể độ nhî̀u giao diện để sử dụng thuận tiện và nhanh chóng. Chương trình chạy trên mạng LAN theo chế độ nhî̀u người sư dụng.

\section{b) Phân tích hệ thông tin nhân sự KBNN}

Khung cánh cưa hệ thổng: là hệ thông tin phân cấp: cấp trung ương, cấp tỉnh, cấp huyện.

Các lĩnh vực: 1) Lĩnh vực tổng quát nhất là "hệ thông tin quán lý nhân sự" - đây là lĩnh vực chính của toàn bộ phần mềm, công việc quản lý lớp các đối tượng là hồ sơ nhân sự. 2) Lĩnh vực dịch vụ ở đây bao gồm việc cung cấp các dịch vụ truyền thông, cập nhật, tìm kiếm thông tịn, in ấn báo cáo, trên các thông tin liên quan đển vấn đề nhân sự. 3) Lĩnh vực kiến trúc: cấu trúc của hồ sơ nhân sự, cấu trúc của các màn hình, cấu trúc của bộ điều khiển các dịch vụ sẽ tạo nên cấu trúc chương trình và các cơ chế hoạt động cưa hệ thống, hệ thống các thư viện. 4) Lĩnh vực cài đặt: hệ điều hành mạng, hệ quán trị cơ sớ dữ liệu.

Phân tích các lĩnh vực thành các hệ con: 1) Hệ thống. 2) Cập nhật [cập nhật sơ đồ tổ chức, danh sách cán bộ, danh sách lên lương, chuyển công tác, cặp tài liệu]. 3) Dữ liệu [thực hiện các chức năng tác động lên tập các bản ghi đó]. 4) Soạn tháo. 5) Báo cáo. 6) Bảo mật. 7) Truyền thông. 8) Trợ giúp. 9) Hệ đều hành mạng. 10) Hệ quán trị CSDL. Trong phân tích và thiết kể, Visual Foxpro 5.0 được dùng làm công cụ phát triển ứng dụng, đây là hệ quán trị CSDL hỗ trợ mạnh mẽ lập trình hướng đối tượng.

Mô hình tĩnh của các đối tượng. Đối tượng liên quan đển nội dung của quản lý (xem hình 1).

Mối quan hệ giữa dổi tượng liên quan dến nội dung và dối tượng hiện thị chúng. Đối tượng lý lịch các nhân liên quan đển đối tượng màn hình hiển thị chúng trong quan hệ "uses' màn hình hiển thị này cûng là một đối tượng, nó được đặt tên là "danh sách cán bộ". Trong màn hình này lại phải có quan hệ với các đối tượng khác, chính những đối tượng này ngầm chứa khá năng hiển thị những phần nội dung của lý lịch cán bộ như hình vẽ trên. Chúng ta sẽ dùng những đối tượng chuẩn thích hợp trong môi trường Visual Foxpro để làm đîêu này.

Mối phần nội dung của nhân sự đến lượt nó lại có tương ứng một đối tượng màn hình hiển thị. Ví dụ phần "Đào tạo" có màn hình hiển thị là "Quá trình đào tạo". Phần "Lương" có tương ứng đối tượng màn hình hiển thị là "Quá trình lương". Các phần khác của lý lịch hoàn toàn tương tự. Chúng ta có mô hình diễn đạt quan hệ tĩnh giữa các đối tượng nói trên như trong hình 2. 


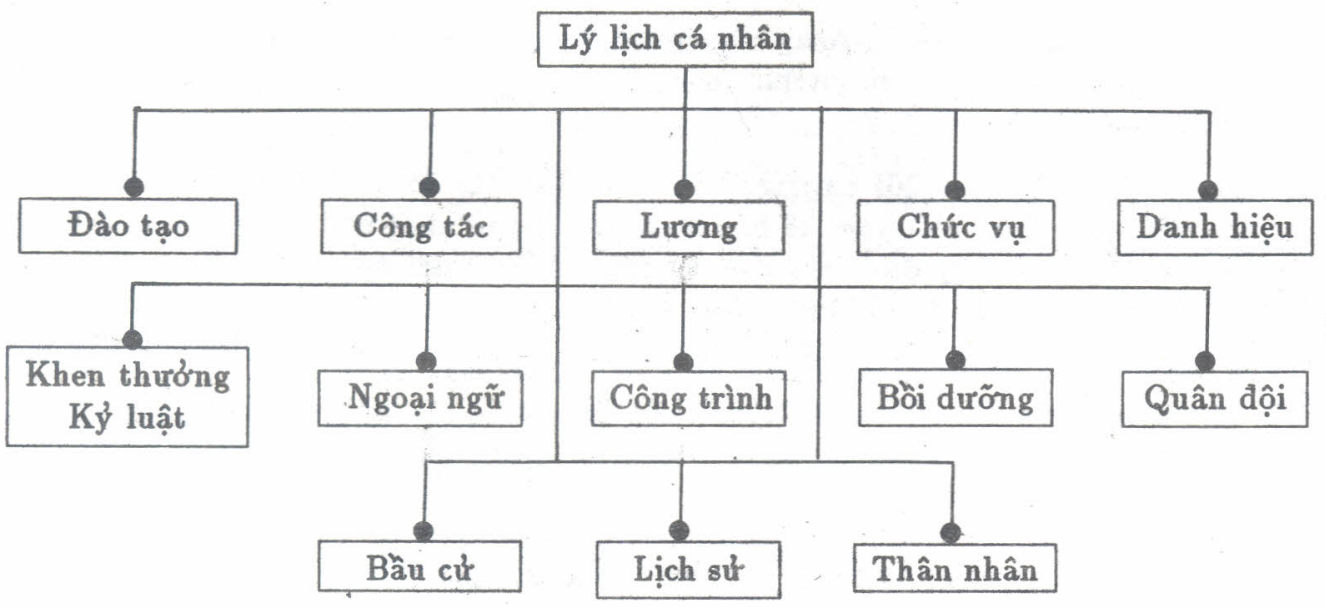

Hinh 1. Quan hệ tînh giữa các đối tượng nội dung quán lý

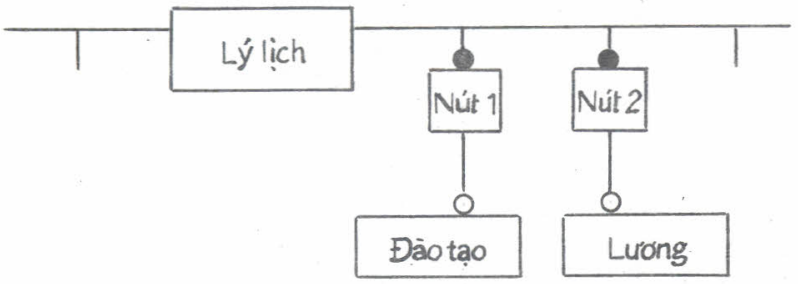

Hinh 2. Mối quan hệ tĩnh giữa đối tượng "nội dung" và "hiển thị"

Đối tượng danh mục và đối tượng màn hình hiển thị. Các dạnh mục cũng là các đối tượng của hệ thông tin và tương tự sẽ có các đối tượng màn hình hiển thị. Ví dụ "Danh mục trình độ học vấn" có đối tượng đặt tên là "dmtdhv.scr" là màn hình hiển thị của nó. Và "Danh mục chức vụ" có đối tượng màn hình "dmcv.scr" là màn hình hiển thị của nó. Các màn hình này chứa các thông tin về nội dung các danh mục, mã của danh mục nên nói chung giống nhau, do đó chúng thuộc vào cùng một lớp (class).

Mô hình ứng xứ. Mô hình ứng xử cưa đối tượng trung tâm của hệ thống thông tin là lý lịch cán bộ được xét tới trong mục này, vì mô hình ứng xử của đối tượng này quyểt định cách xử lý của toàn bộ hệ thống. Do yêu cầu cưa nâng cao sự tiện ích trong vấn đề cập nhật thông tin của hồ so

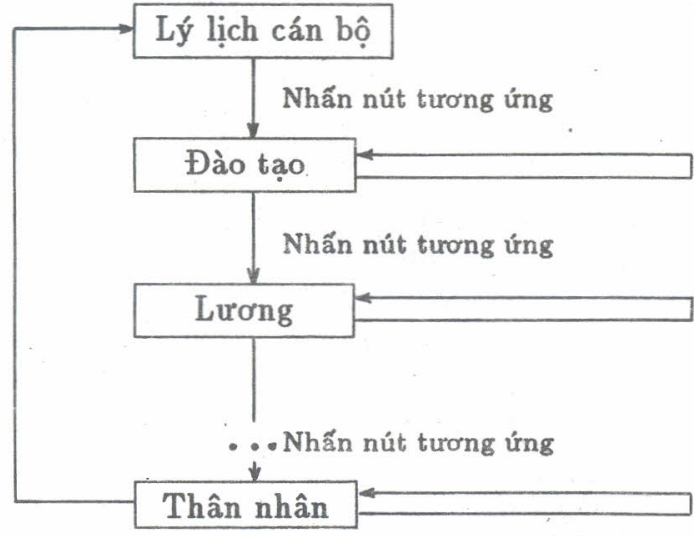

Đóng/mớ cứa sỗ

Thực hiện các thao tác cập nhật

Đóng/mớ cứra sỗ

Thực hiện các thao tác cập nhật

Đóng/mớ cứra sỗ

Thực hiện các thao tác cập nhật

Hình 9. Otomat Mealy thể hiện mô hình ứng xử của đối tượng lý lịch 
cán bộ nên người sừ dụng có nhu cầu cập nhật thông tin có thể đồng thời cùng một lúc các phần của lý lịch trên các màn hình truy nhập khác nhau. Do đó công nghệ nhiều màn hình giao diện (Multi Document Interfacing Technique - MDI) phải được sử dụng trong hệ thổng này. Với lý do trên mô hình ưng xử cho đối tượng trung tâm được thể hiện bằng Otomat Mealy, ở đó chấp nhận các hành động song hành (xem [2]), như trong hình 3.

\section{c) Thiết kể hướng đổi tượng hệ thông tin nhân sự KBNN}

Phần này sẽ trình bày các đối tượng cơ bản của không gian lời giải được thiết kế ra sao trong khung cảnh thiết kế của môi trường thiết kế và lập trình của hệ quản trị cơ sở dữ liệu Visual Foxpro 5.0.

Xác định đối tượng trong không gian lời giåi. 1) Các đội tượng màn hình chuyển tải thông tin về các danh mục (từ điển). 2) Các đội tượng thực hiện các chức năng về cập nhật. 3) Các đối tượng chư động thực hiện các chức năng xử lý trên tập hợp các bản ghi của các bảng liên quan. 4) Các đối tượng thực hiện các báo cáo liên quan đển vấn đề nhân sự. 5) Các đối tượng thực hiện các chức năng về bảo mật.

Xây dựng các đặc tå cho các đối tượng, các lớp, các thành phần cơ bån của lời giải. Các lớp đối tượng sau đây cần được xây dưng: lớp các chương trình thực hiện các chức năng của ứng dụng; lớp các đối tượng màn hình hiển thị các danh mục; lớp các đối tượng để biểu diễn các phép hiển thị kiểu danh sách thường có đối với các bài toán nhập, sữa dữ liệu của một CSDL (các Grid); lớp các toolbar đặc trưng của hệ thổng; lớp các nút tác động cơ bản.

Sau đây là các lớp cu thể được thiết kế cho bài toán quản lý nhân sự nhiều màn hình giao diện (MDI), các lớp này liệt kê trong khung cưa sổ ở hình 4.

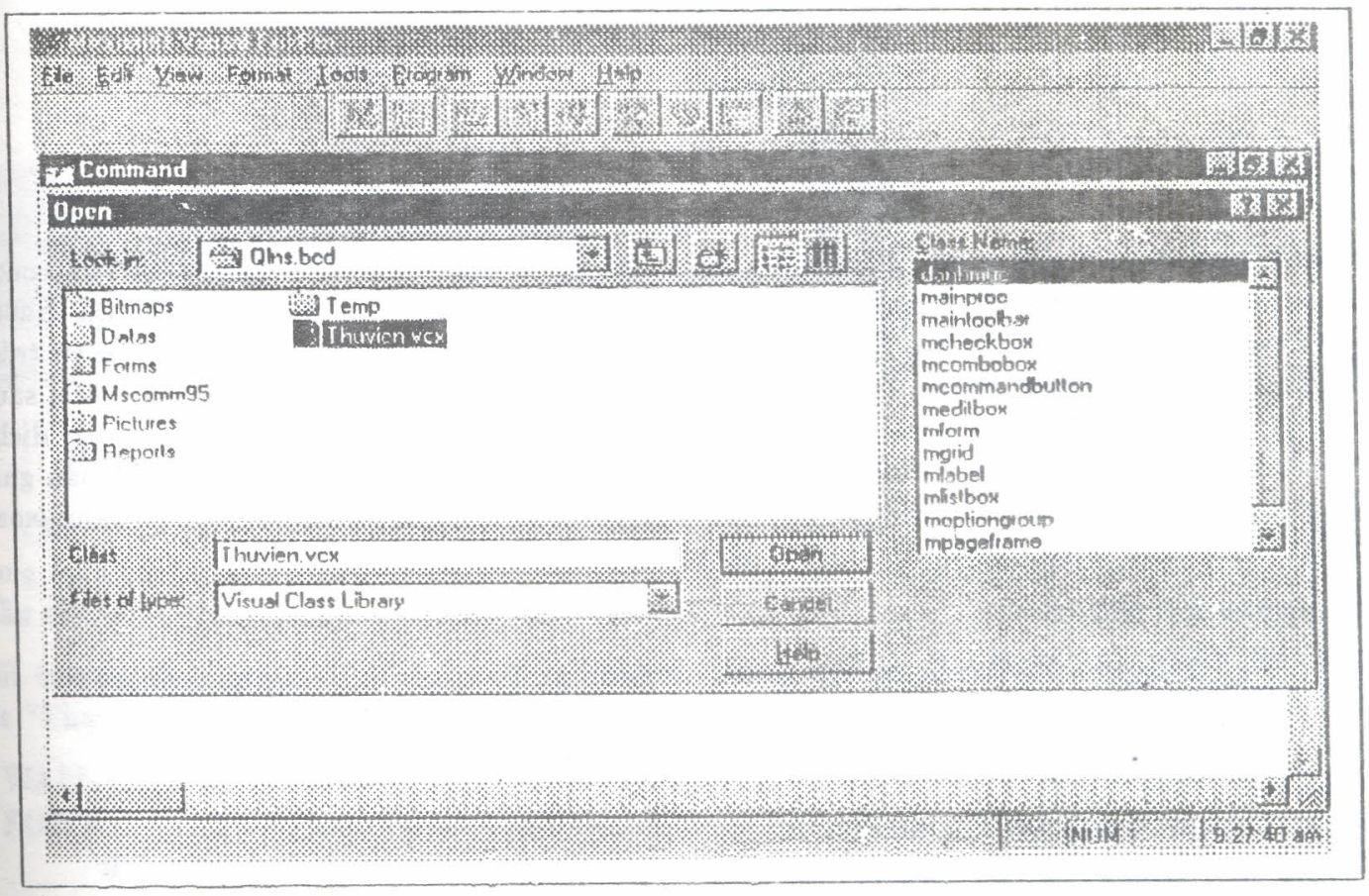

Hinh 4. Cửa sổ thiểt kế các lớp đối tượng

Các class được thiết kể để phù hợp với ý đồ phục vụ lời giải bài toán, theo cách như sau:

Lớp các chương trình ứng dụng. Trong hình 5 là các thuộc tính và các tác động của lớp mainproc: giải quyết chức năng như chương trình chính cưa hệ thông tin. Mã của lóp mainproc được đưa ra trong khung văn bån bên cạnh. 


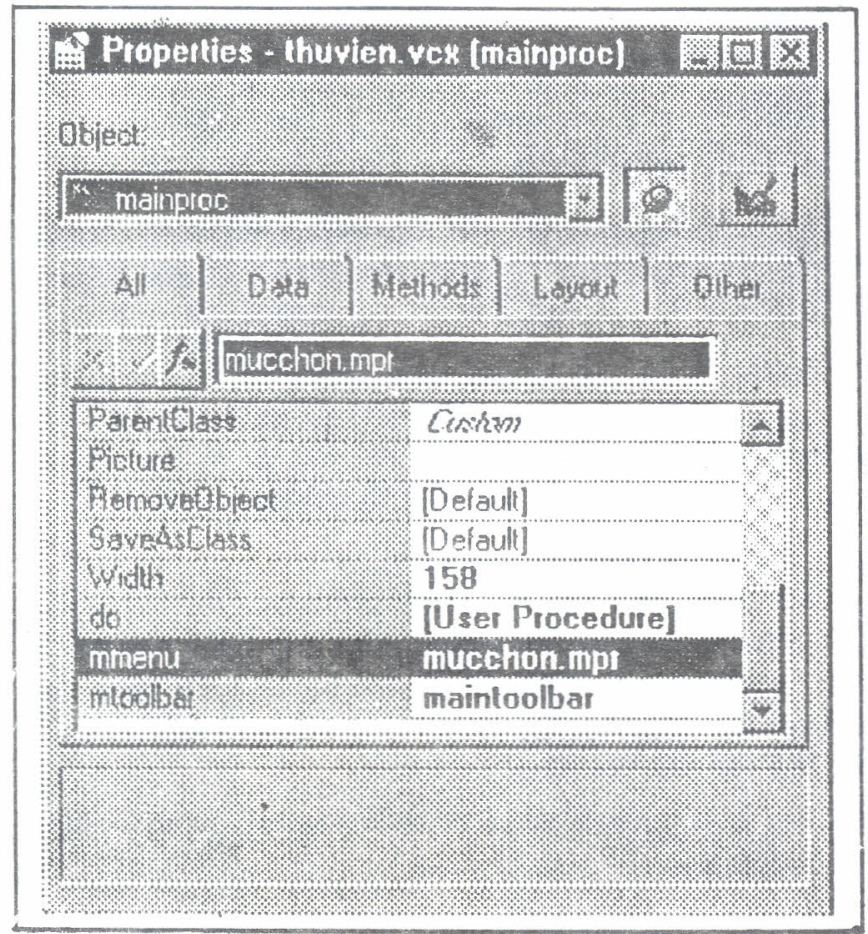

Hinh 5. Màn hình thiết kế chương trình chính
Screen. WindowState $=2$

If not empty (this.mmenu) DO (this.mmenu)

Endif

If not empty(this.mtoolbar)

Public mtool

mtool $=$ CreateObj(this.mtoolbar) mtool.Show()

Endif

1Buffer $=$ SPACE $(100)$

$=$ GetPrivStr(TuyChon], [ManHinh], [] @1Buffer, LEN(1Buffer), WinDir + [QLNS.INI])

IF! ALLTRIM(1Buffer) $=\mathrm{CHR}(0)$

DO CASE

CASE VAL(1Buffer) $=1$

DO FORM DSNV

CASE VAL(1Buffer) $=2$

DO FORM CapTL

CASE YAL(1Buffer) $=3$

DO FORM HOIDAP WITH 'DSNV'

CASE VAL (1Buffer) $=4$

DO FORM BAOCAO

CASE VAL(1Buffer) $=5$

DO FORM HDSD

ENDCASE

ENDIF

READ EVENTS

Lớp các toolbar. Lớp toolbar làm chức năng điều khiển chương trình theo đúng tinh thần của một Otomat Mealy, nó bao gồm các nút chức năng khác nhau, mỗi nút chức năng này lại thuộc vào lớp đối tượng cơ bản của Visual Foxpro. Trong toolbar chúng ta đánh số các button từ trái qua phải gồm 8 nút bấm chức năng, sau đó ta sẽ thiết kể từng nút chức năng theo các bước sau đây. Nút một: dịch chuyển tới bản ghi đầu. Nút hai: dịch chuyển tới bản ghi trước. Nút ba: dịch chuyển tởi bản ghi sau. Nút bốn : dịch chuyển tới bản ghi cuối. Nút năm: bổ sung một bản ghi mới. Nút sáu: ghi lại bản ghi đang cập nhật. Nút bảy: bỏ qua thay đổi vừa xong. Nút tám: xóa một bản ghi. Nút chín: đóng cửa sỗ đang hoạt động.

Hàm thành phần nút thứ nhất

IF'2' \$ GETFLDSTATE(-1) OR ' 4 ' \$

GETFLDSTATE(-1);

OR '3' \$ GETFLDSTATE(-1)

LOCAL Bien

DO FORM YesNo WITH 'Dũ̃ liệu đã

thay đổi. Ban có ghi lại không?’ TO Bien

IF Bien=1

=TABLEUPDATE()
ELSE
ENDIF


STORE .F. TO This.Enabled,

This.Parent.mCommandButton2.Enabled

STORE.T. TO

Các hàm thành phần khác của các nút chức năng được lập một cách tương tự, chúng tôi không đưa ra ở đây.

Các đổi tượng phục vụ thiểt lập các từ điênn hệ thổng. Các danh mục được thiết lập trong hệ thông tin nhằm mục đích giảm thời gian nhập liệu cho người sử dụng, dồng thời tạo nên một sự thống nhất về dữ liệu có cùng ngũ̃ nghĩa trong hệ thống. Các danh mục này cũng tạo nên một sự thống nhất chung do quy định của Ban tổ chức Trung ương Đảng và Ban tổ chức Chính phủ. Các danh mục được hiển thị và mang tải thông tin bởi các màn hình hiển thị.

Các đổi tượng phục vụ cho việc Cập nhật: sơ đồ tổ chức, danh sách cán bộ, danh sách lên lương, chuyển công tác, cặp tài liệu. Trong đó như là một minh họa, đối tượng liên quan với danh sách cán bộ được thể hiện trong hình 6 .

Trong đối tượng này có đối tượng thành phần như sau:

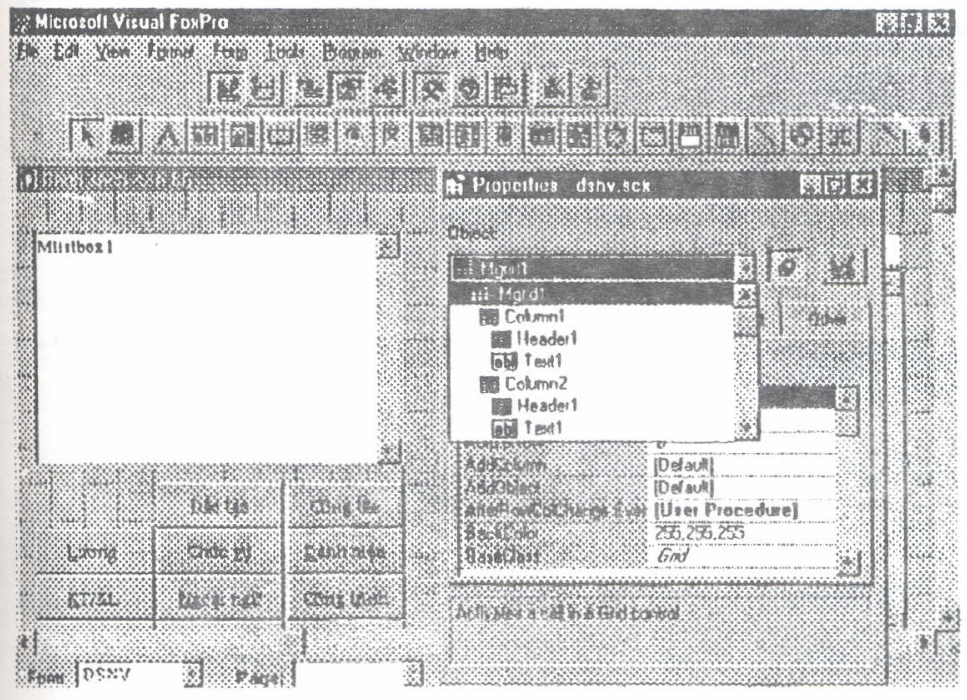

\author{
Mgrid1 \\ Column 1 \\ Header 1 \\ Text1 \\ Column2 \\ Header 1 \\ Text1 \\ Column 3 \\ Header 1 \\ Text1 \\ Mcommandbutton1 \\ Mcommandbutton 14 \\ Mtextbox1 \\ Mtextbox2 \\ Mcommandbutton 16
}

Hình 6. Màn hình thiết kế đối tượng danh sách cán bộ

Chú ý rằng cùng một lúc có thể khởi động nhiều màn hình tương ứng với các nút chức năng trong màn hình danh sách cán bộ, và việc lựa chọn làm việc với màn hình nào đó sẽ dùng menubar phần cửa sổ để lựa chọn.

Đối tượng liên quan đển chức năng chuyển công tác được thể hiện trong hình 7 . Trong đó nút "Thực hiện" có hàm kèm theo, nó được thực hiện khi nút được nhấn:

WAIT WINDOW 'Đợi một chút...' NOWAIT

FOR I=1 TO This.Parent.mLisBox1.ListCount

If This.Parent.mListBox1.Selected(I)

SELECT mCBLL

Go TOP

SKIP I-1

IF EMPTY(MaNgach)

LOOP

ENDIF 


\author{
SELECT DM_BaC \\ LOCATE FOR MaNgach=mCBLL.MaNgach AND MaMuc= \\ mCBLL.MaBac+1. \\ IF FOUND() \\ SELECT Luong \\ CALCULATE MAX(NgayXep); \\ FOR $\mathrm{MaNhanSu}=\mathrm{mCBLL} . \mathrm{MaNhanSu}$; \\ TO $\mathrm{mNgay} X \mathrm{ep}$ \\ REPLACE MaBac WITH DM_Bac.MaMuc, NgayXep WITH MyDate; \\ FOR MaNhanSu=mCBLL.MaNhanSu AND NgayXep=mNgayXep \\ ENDIF \\ ENDIF \\ ENDFOR \\ This.Parent.mComboBox1.InterActiveChange() \\ WAIT WINDOW 'Đã thực hiện xong”
}

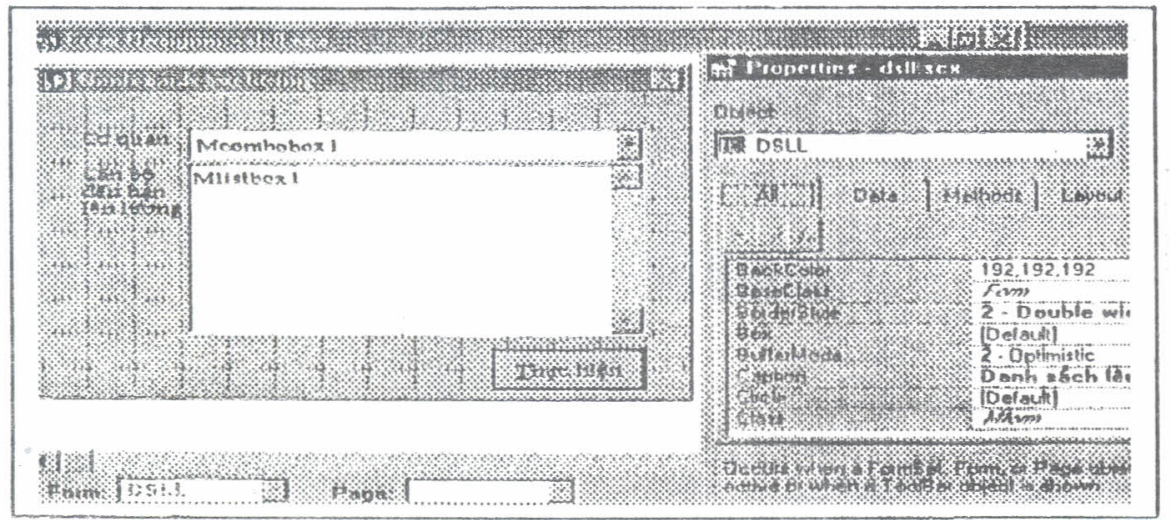

Hình 7. Đối tượng liên quan đển chức năng chuyển công tác

Chú ý : Các đối tượng liên quan với chức năng sơ đồ tổ chức, danh sách lên lương, xây dựng cặp tài liệu làm tương tự.

Thiết kể chương trình chinh bao gồm các công việc

1) Thiết kể màn hình chính.

2) Thiết kế các menubar.

3) Thiết kế các báo cáo (dùng công cụ thiết lập report của Visual Forpro để làm report).

\title{
IV. KẾT LUẬN
}

Phân tích và thiết kế hướng đối tượng tăng tốc độ phát triển phần mềm rất nhiều. Bằng sự phân cấp lớp cưa các đối tượng, việc viết tài liệu thiết kế một hệ thông tin cũng trở nên dễ dàng hơn. Việc bảo trì cũng thuận lợi vì các chức năng được đảm trách bởi những đối tượng; thay đổi các hành vi của hệ thống được thực hiện bởi việc gửi và tiếp nhận các thông diệp từ đối tượng này tới đối tượng khác nên dòng thực hiện logic của ứng dụng dễ kiểm soát hơn. Việc sửa đổi trình ứng dụng theo hướng đối tượng thuận lợi hơn vì những sữa đổi trên một lớp sẽ tác động lên các lớp cấp dưới và các đối tượng trực thuộc. Ví dụ khi muốn chuyển các giao diện sang phông chữ khác việc thay đổi sẽ rất nhanh chóng.

Trên cơ sở tiếp cận hướng đối tượng vì̛a trình bày đơ trên, việc phân tích và thiết kế hệ thông tin $\mathrm{KBNN}$, mặc dù có khối lượng công việc rất lớn song hoàn toàn có thể kiẻ̉m soát được. 
Kho bạc Nhà nước thực tế là cơ quan quàn lý ngân sách của đất nước. Việc sử dụng có hiệu quá nguồn ngân sách này mang một ý nghĩa hết sức to lớn. Hệ trợ giúp ra quyểt định là một nhu cầu hiện tại và trong tương lai cưa lãnh đạo ngành Tài chính nói chung và của KBNN noói riêng. Để tiến tới xây dựng hệ trợ giúp quyết định cho KBNN cần phải tiến hành những công việc sau: i) Xây dựng và hoàn thiện hệ thông tin kế hoạch nghiệp vụ. ii) Xây dựng và hoàn thiện hệ thông tin thống kê KBNN. iii) Xây dựng và hoàn thiện hệ thông tin phục vụ lãnh đạo KBNN. iv) Xây dựng tập hợp mô hình toán và thống kê. v) Xây dựng Cơ sở tri thức tài chính. Đó là những thành phần cần có cưa một hệ trợ giúp ra quyết định. Những vấn đầ liên quan đến phân tích và thiết kể hệ trợ giúp quyết định cho lãnh đạo ngành KBNN sẽ được đề cập trong một bài báo khác.

\section{TAI LṬ̣̂U THAM KHẢO}

[1] Nguyễn Văn Ba, Phân tích hệ thống (hướng chức năng và hướng đối tượng), Đại học Bách khoa Hà Nội, 1997.

[2] Đoàn Văn Ban, Phân tích, Thiết kế và lập trình hướng đối tượng, Nhà xuất bản Thống kê, 1997.

[3] BITCO, Phân tích và thiết kế chi tiết Hệ thống thông tin Kho bạc Nhà nước trong điều kiện áp dụng luât Ngân sách 1997, Ban chỉ đạo chương trình quốc gia về CNTT, 1997.

[4] Roger S. Pressman, Software Engineerig: A Practitioner's Approach, McGraw-Hill, 1986.

(1) Công ty Công nghệ thông tin thương mai (BITCO).

Nhận bài ngày 25-3-1998

(2) Khoa Công nghệ thông tin, Trường Dại học Bách khoa Hà Nội.

\section{THÔNG BÁO TUYẾN NGHIÊN CƯU SINH NĂM 1999}

Viện Công nghệ thông tin, Trung tâm Khoa học tự nhiên vả Công nghệ Quốc gia thông báo tuyển nghiên cứu sinh năm 1999 về các linhh vực sau:

1. Lý thuyết xác suất và thống kê toán học (MS 10104 )

2. Toán học tính toán (MS 10107 )

3. Điều khiển học toán học (MS 10108 )

4. Đảm báo toán học cho MT \& hệ thống tính toán (MS 01 10)

5. Điều khiển học KT \& lý thuyểt thông tin (MS 205 01)

6. Kỹ thuật tính toán (MS 20503 )

7. Điều khiển học kinh tế (MS 50220 ).

Thời gian tỗ chức thi: Dự kiến trong tháng $5 / 1999$ (theo sự chỉ đạo thống nhất của Bộ Giáo dục và Đào tạo)

Thời hạn: Đăng ký danh sách và hồ sơ dự thi tuyển NCS năm 1999 xin gưi về Bộ phận quán lý đào tạo NCS của Viện CNTT, Đường Hoàng Quốc Việt, Nghĩa Đố, Cầu Giấy, Hà Nội, ĐT: 7561898 trước 30/4/1999 